\title{
PERIPARTUM CARDIOMYOPATHY: A REVIEW
}

\author{
Rajat Jain ${ }^{1}$, Vaishali Sikerwar², Subhash Rajpoot ${ }^{3}$, Kshitiz Nath $^{4}$ \\ ${ }^{1}$ Associate Professor, Department of Medicine, M.L.B. Medical College, Jhansi. \\ 2 Junior Resident, Department of Medicine, M.L.B. Medical College, Jhansi. \\ ${ }_{3}^{3}$ Lecturer, Department of Pathology, M.L.B. Medical College, Jhansi. \\ ${ }^{4}$ Lecturer, Department of Medicine, M.L.B. Medical College, Jhansi.
}

\begin{abstract}
Peripartum Cardiomyopathy is a pregnancy associated rare but severe myocardial disease. The incidence of PPCM is about 1 in 3186 live births in United States. Causes include viral infections, toxins, environmental and geographic factors, familial predisposition, Hormonal abnormalities, haemodynamic burden of pregnancy, malnutrition, inflammation, etc. NT-proBNP, Cathepsin D, tyrosine kinase SFlt1 may be elevated and can be used as biomarkers to diagnose PPCM. Restriction of dietary sodium, beta-blockers, diuretics-thiazide and furosemide, in lowest possible doses can be given for symptomatic management. Prognosis of PPCM is positively related to the recovery of ventricular failure. Only about 50\% women with PPCM recover baseline ventricular function within 6 months of delivery. Failure of heart size to return to normal is associated with increased mortality and morbidity. Future pregnancies are not recommended in patient with PPCM, as there is an increased risk for recurrence of PPCM in the subsequent pregnancy.
\end{abstract}

\section{KEYWORDS}

Peripartum, Cardiomyopathy, Pregnancy.

HOW TO CITE THIS ARTICLE: Jain R, Sikerwar V, Rajpoot S, et al. Peripartum cardiomyopathy: a review. J. Evolution Med. Dent. Sci. 2016;5(43):2714-2717, DOI: $10.14260 /$ jemds/2016/634

\section{INTRODUCTION}

Peripartum Cardiomyopathy is a pregnancy associated rare but severe myocardial disease. It is a type of Dilated Cardiomyopathy with unclear aetiology.[1] The disease is heterogeneous and seems to have important phenotypic variations in different geographical areas.[2] PPCM is a diagnosis of exclusion. ${ }^{[3]}$ Therefore, all other causes of Dilated Cardiomyopathy with Heart Failure must be thoroughly excluded before accepting the designation of PPCM. PPCM is defined as non-familial form of Dilated Cardiomyopathy. ${ }^{[4]}$ It is diagnosed when the following four criteria are met.

1. Heart Failure develops in the last month of pregnancy or within 5 months of delivery.

2. Absence of an identifiable cause for the cardiac failure.

3. Absence of recognizable heart disease prior to the last month of pregnancy.

Additional Criteria-

4. Echocardiography criteria of left ventricular systolic dysfunction, i.e. ejection fraction $\leq 45 \%$ or fractional shortening $<30 \%$ or both or left ventricular end diastolic dimension $\geq 2.7 \mathrm{~cm} / \mathrm{m}^{2}$.[5]

The strict time limit used in its diagnostic criteria was intended to exclude congenital and acquired causes of HF that usually manifests by the second trimester.[6]

\section{INCIDENCE}

The incidence of PPCM was one case per 1374 live births in an Indian study.[7] In the US, the incidence ranges from 1 in 1149 to 1 in 4350 live births with a mean of 1 in 3186 live

Financial or Other, Competing Interest: None.

Submission 14-04-2016, Peer Review 08-05-2016,

Acceptance 14-05-2016, Published 30-05-2016.

Corresponding Author:

Dr. Rajat Jain,

Associate Professor

Department of Medicine,

M.L.B. Medical College, Jhansi.

E-mail: today.tomorrow.abha@gmail.com

DOI: $10.14260 /$ jemds $/ 2016 / 634$ live births has been reported from Haiti.[12] and around 1:100 in Africa.[13]

The rising incidence is attributable to increased awareness and reporting, socio-economic changes with rising maternal age, infertility related treatments thereby leading to multifetal pregnancy.

\section{Aetiology}

PPCM is an uncommon disorder with variable and sometimes grave prognosis with an unknown origin. Although, it has been described as a non-familial variety, familial clustering is seen in different parts of the world, i.e. reports of about $16 \%$ PPCM patients with positive history of heart failure suggesting genetic aspects in PPCM.[3,4,14] or due to sharing of common environmental and geographical location, thus careful family history should be taken in all PPCM cases.

As pregnancy is a relatively immunocompromised state, role of viral infection in inducing PPCM cannot be denied but the results are controversial as reviewed by Sella et al.[15] The highly variable prevalence of myocarditis in PPCM patients ranging from $8.8 \%$ to $78 \%$ suggests that in some cases viral infections may be among the trigger for PPCM.[15] Reactivation of primary latent viral infection usually in childhood due to lowered immune defense can be of potential importance.

Hormonal abnormalities, haemodynamic burden of pregnancy, malnutrition, inflammation and apoptosis are other potential causes.[16] The strongest risk factor for PPCM appears to be African American ethnicity.[17] Other reported risk factors include advanced maternal age, gestational hypertension or pre-eclampsia.[18] Symptoms of heart failure in patients with PPCM are often attributed to pre-eclampsia and pregnancy induced hypertension or both conditions, resulting in a delay of PPCM diagnosis and treatment. The differentiating feature being the fact that PIH is not likely to cause marked LV systolic dysfunction in young women and hypertensive pulmonary oedema is due mostly to 
exacerbation of diastolic dysfunction and not to systolic dysfunction.[19]

Similar is the case with pre-eclampsia, which can also present with signs and symptoms of Heart Failure, but systolic function is usually preserved.[20,21,22,23]

Multifetal pregnancies, multiparty have been considered traditionally to be risk factors.[3] Older maternal age is also strongly associated with PPCM. Although, the disease has been reported in women between the ages of 16 and 44 years, the mean age of women with PPCM in the United States has ranged from 27 to 33 years with $>60 \%$ of patient reported in one study to be $>30$ years of age.[24]

Prior to toxin exposure (Example cocaine) and prolonged use of tocolytic agents, i.e. the use of agents to prevent premature labor for more than 4 weeks is associated with PPCM.[25]

During pregnancy, blood volume and cardiac output increase.[5] In addition, afterload decreases because of relaxation of vascular smooth muscles.[26] These changes cause a brief, reversible hypertrophy of the left ventricle to meet the needs of developing fetus and mother.[27] This transient LV dysfunction resolves shortly after birth.[25,27] Pearson et al suggested that PPCM might be due in part to an exaggerated disease in left ventricular function. ${ }^{[5]}$

Prolactin has been implicated in the aetiology of PPCM. Hilfeker Kleiner et al[28,29], discovered that PPCM develops in mice bred to have a cardiomyocyte specific deletion of STAT3, a protein that plays a key role in many cellular processes such as cell growth and apoptosis. The deletion of STAT3 led to enhanced expression of cardiac Cathepsin D, which leads to oxidative stress mediated cleavage of hormone prolactin into smaller biologically active subfragments, $16 \mathrm{kDa}$ protein which is a major inciting feature in development of PPCM. This 16-kDa prolactin up-regulates miR146a, which mediates its adverse effects in endothelial cells and is released in microparticles (Exosomes) into the circulation from where it affects cardiomyocytes. Endothelial Metalloproteinase (EMP) could directly demonstrate endothelial damage in PPCM.[30] Chronic inflammatory process also plays a part as denoted by elevated CRP levels in PPCM patient. ErbB4 levels are reduced in the left ventricular tissue of PPCM patients. [31]

Deficiency of selenium increases cardiovascular susceptibility to viral infections, hypertension and hypocalcemia.[32,33] However, the results of studies proving the possible role of selenium have not been convincing.

\section{Clinical Evaluation of Patients with PPCM}

Broad spectrum of signs and symptoms is reported in PPCM patients. PPCM is diagnosed in any woman in last month of pregnancy or within 5 months post-partum with the following symptoms - breathlessness, fatigue, exercise intolerance, peripheral oedema, weight gain (Water retention), chest pain, cough, palpitations, paroxysmal nocturnal dyspnea, weakness and signs - tachypnea, tachycardia, raised JVP, pedal oedema, arrhythmias, hepatomegaly and bilateral basal crepts.

\section{Biomarkers and Diagnosis of PPCM}

NT-ProBNP is a marker usually markedly elevated in most PPCM patients. It is the only commercially available marker for efficient screening of PPCM.[14,34] Asymmetric Dimethylarginine (ADMA) - marker for endothelial dysfunction and cardiovascular risk may be elevated. Levels of Cathepsin D show an increased activity in plasma of patients with PPCM.[14,35,36] Soluble FMS-like tyrosine kinase SFlt1-biomarker of pre-eclampsia supposed to clear rapidly after delivery is increased in PPCM. MiRNA is specifically increased in PPCM patients compared with healthy postpartum women and patients with Dilated Cardiomyopathy. For the markers such as $16-\mathrm{kDa}$ protein, IFN gamma, ADMA, Cathepsin D, SFlt 1, microRNA 146a, diagnostic accuracy needs to be further evaluated. Failure to normalize a biomarker profile including NT-ProBNP, oxy LDL, IFN gamma, prolactin, etc. is associated with adverse outcome in pt. with PPCM.[34]

\section{Management}

Late in pregnancy beta-blockers, diuretics-thiazide and furosemide in lowest possible doses can be given. Preload reduction can also be achieved by administration of vasodilators, e.g. nitrates. Restriction of dietary sodium also reduces preload. Afterload reduction is best achieved by Angiotensin Converting Enzyme Inhibitors, but not used due to their teratogenic potential. After delivery the standard treatment of heart failure is recommended in PPCM including beta blockers, ACE inhibitors, AT-1 blockers, mineralocorticoid receptor antagonist and diuretics. Use of Milrinone has also been advocated, as it has vasodilatory properties for both the systemic and pulmonary circulation. ${ }^{[37]}$ In case of cardiogenic shock, intravenous inotropes (e.g. dobutamine) can be considered. Left ventricular thrombus is common in women with PPCM, whose ejection is less than 35\%.[27,38] Warfarin should be given to these postpartum women and heparin or a lowmolecular-weight heparin should be given to women who are pregnant and have low ejection fraction. [39]

Immunosuppressive and anti-inflammatory are usually not recommended. Bromocriptine, a dopamine antagonist that inhibits prolactin secretion prevented the expected deterioration in the size of the left ventricle and systolic function when given in addition to standard heart failure therapy in women with PPCM. A general agreement among experts (study group of PPCM of the Heart Failure Association/European Society of Cardiology) suggest continued therapy with standard heart failure medications for a minimum of 12 months.[12]

Management of Compensated Heart Failure in PPCM.[38,40] The non-pharmacological therapies including low sodium diet, fluid restriction and light daily activity.

Antepartum management of PPCM includes beta blockers (Carvedilol, metoprolol), vasodilators (Hydralazine, nitrates), digoxin and diuretics. For the management of postpartum PPCM Angiotensin-Converting Enzyme inhibitors, Angiotensin Receptor Blockers, Aldosterone Antagonists can be added to the treatment

Left ventricular thrombus is common in women with PPCM, whose ejection fraction is less than $35 \%$. Warfarin should be given to postpartum women whose ejection fraction is $35 \%$ or less, and heparin or a low-molecularweight heparin should be given to women who are pregnant and have a similar ejection fraction. ${ }^{[41,42]}$

\section{Management of Decompensated Heart Failure in PPCM. ${ }^{[42,43]}$}

Maintaining airway, breathing and circulation of the patient are of the prime importance. Intravenous loop diuretics, 
intravenous vasodilators (e.g. nitroglycerin infusion), positive inotropic agents can be used. Beta blockers are usually avoided in acute decompensated heart failure.

Medical therapy can be successful in patients with PPCM and mechanical cardiovascular support may be required in the form of assist devices, which work as a bridge-torecovery or bridge-to-transplantation.

The various assist devices being used like intra-aortic balloon pump, left ventricular assist devices, extracorporeal membrane oxygenation. Extracorporeal membrane oxygenation is of benefit in women with PPCM, who had persistent pulmonary oedema with hypoxemia.

Patients with elevated serum markers of inflammation (CRP and TNF alpha) after treatment with pentoxifylline on top of conventional heart failure therapy suggesting potential benefit of anti-TNF alpha treatment.[44]

A pilot study in South Africa reported highly beneficial effect of prolactin blocker bromocriptine on top of heart failure medication in patients with acute onset PPCM. [45,46]

\section{Future Risks and Recurrence}

Prognosis of PPCM is positively related to the recovery of ventricular failure.[41] Only about 50\% women with PPCM recover from baseline ventricular function within 6 months of delivery.[41] Failure of heart size to return to normal is associated with increased mortality and morbidity.[5] Future pregnancies are not recommended in patients with PPCM, as there is an increased risk for recurrence of PPCM in the subsequent pregnancy.

\section{REFERENCES}

1. Johnson-Coyle L, Jensen L, Sobey A. Peripartum cardiomyopathy: review and practice guidelines. Am J Crit Care 2012;21(2):89-98.

2. Uri Elkayam. Clinical Characteristics of peripartum cardiomyopathy in the United States: diagnosis, prognosis, and management. J Am CollCardiol 2011;58(7):659-70.

3. SliwaK, FettJ. ElkayamU. Peripartum cardiomyopathy. Lancet 2006;368,(9536):687-693.

4. Sliwa K, Hilfiker-Kleiner D, Petrie MC, et al. Current state of knowledge on aetiology, diagnosis, management, and therapy of peripartum cardiomyopathy: a position statement from the heart failure association of the European society of cardiology working group on peripartum cardiomyopathy. Eur J Heart Fail 2010;12(8):767-778.

5. Pearson GD, Veille JC, Rahimtoola S, et al. Peripartum cardiomyopathy. National heart, lung, and blood institute and office of rare diseases (National Institutes of Health) workshop recommendations and review. JAMA 2000;283(9):1183-1188.

6. Demarkis JG, Rahimtoola SH. Peripartum cardiomyopathy. Circulation 1971;44(5):964-68.

7. Pandit V, Shetty S, Kumar A, et al. Incidence and outcome of peripartum cardiomyopathy from a tertiary hospital in South India. Trop Doct 2009;39(3):168-9.

8. Chapa JB, Heiberger HB, Weinert L, et al. Prognostic value of echocardiography in peripartum cardiomyopathy. Obstetrics and Gynaecology 2005;105(6)1303-1308.
9. Adesanya CO, Anjorin FI, Adeoshun IO, et al. Peripartum cardiac failure. A ten year follow-up study. Tropical and Geographical Medicine 1989;41(3):190-196.

10. Hilfiker-Kleiner D, Meyer GP, Schieffer E, et al. Recovery from postpartum cardiomyopathy in 2 patients by blocking prolactin release with bromocriptine. Journal of the American College of Cardiology 2007;50(24):23542355.

11. Amos AM, Jaber WA, Russell SD. Improved outcomes in peripartum cardiomyopathy with contemporary. American Heart Journal 2006;152(3):509-513.

12. Fett JD, Christie LG, Carraway RD, et al. Five-year prospective study of the incidence and prognosis of peripartum cardiomyopathy at a single institution. Mayo Clin Proc 2005;80(12):1602-6.

13. Sanderson JE, Adesanya CO, Anjorin FI, et al. Postpartum cardiac failure-heart failure due to volume overload? AM Heart J 1979;97(5):613-621.

14. Haghikia A, Podewski E, Libhaber E, et al. Phenotyping and outcome on contemporary management in a German cohort of patients with peripartum cardiomyopathy. Basic Res Cardiol 2013;108(4):366.

15. Selle T, Renger I, Labidi S, et al. Reviewing peripartum cardiomyopathy: current state of knowledge. Future Cardiol 2009;5(2):175-189.

16. Mielniczuk LM, Williams L, Davis DR, et al. Frequency of peripartum cardiomyopathy. Am J Cardiol 2006;97(12):1765-8.

17. Gentry MB, Dias JK, Luis A, et al. African-American women have a higher risk for developing peripartum cardiomyopathy. Journal of the American College of Cardiology 2010;55(7):654-659.

18. Mielniczuk LM, Williams K, Davis DR, et al. Frequency of peripartum cardiomyopathy. American Journal of Cardiology 2006;97(12):1765-1768.

19. Bibbins-Domingo K, Pletcher MF, Lin F, et al. Racial differences in incident heart failure among young adults. N Engl J Med 2009;360:1179-1190.

20. Thompson JA, Hays PM, Sagar KB, et al. Echocardiographic left ventricular mass to differentiate chronic hypertension from preeclampsia during pregnancy. Am J Obstet Gynaecol 1986;155(5):994-9.

21. Simmons LA, Gillin AG, Jeremy RW. Structural and functional changes in left ventricle during normotensive and preeclamptic pregnancy. Am J Physiol Heart Circ Physiol 2002;283(4):1627-33.

22. Hamad RR, Larsson A, Pernow J, et al. Assessment of left ventricular structure and function in preeclampsia by echocardiography and cardiovascular biomarkers. J Hypertens 2009;27(11):2257-64.

23. Dennis AT. Cardiac function in women with preeclampsia. A gateway to Melbourne's research publication 2010 .

24. Elkayam U, Akhter MW, Singh H, et al. Pregnancyassociated cardiomyopathy: clinical characteristics and a comparison between early and late presentation. Circulation 2005;111(16):2050-5.

25. Ntusi NB, Mayosi BM. Aetiology and risk factors of peripartum cardiomyopathy: a systematic review. Int J Cardiol 2009;131(2):168-79. 
26. Ramaraj R, Sorrell VL. Peripartum cardiomyopathy: causes, diagnosis, and treatment. Cleve Clin J Med 2009;76(5):289-296.

27. Tidswell M. Peripartum cardiomyopathy. Crit Care Clin 2004;20(4):777-788.

28. Hilfiker-Kleiner D, Sliwa K, Drexler H. Peripartum cardiomyopathy: recent insights in its pathophysiology. Trends Cardiovasc Med 2008;18(5):173-179.

29. Baruteau AE, Leurent G, Martins R, et al. Peripartum cardiomyopathy in the era of cardiac magnetic resonance imaging: first results and perspectives. Int J Cardiol 2010;144(1):143-145.

30. Melchiorre K, Sutherland GR, Baltabaeva A, et al. Maternal cardiac dysfunction in women with preeclampsia in term. Hypertension 2011;57(1):85-93.

31. Walenta K, Schwarz V, Schirmer SH, et al. Circulating microparticles as indicators of peripartum cardiomyopathy. Eur Heart J 2012;33(12):1469-1479.

32. Demakis JG, Rahimtoola S, Sutton GC, et al. Natural course of peripartum cardiomyopathy. Circulation 1971;44(6):1053-1061.

33. Melvin KR, Richardson PJ, Olsen EG, et al. Peripartum cardiomyopathy due to myocarditis. $\mathrm{N}$ Engl J Med 1982;307(12):731-734.

34. Forster O, Hilfiker-Kleiner D, Ansari AA, et al. Reversal of IFN-gamma, ox LDL and prolactin serum levels correlate with clinical improvement in patients with peripartum cardiomyopathy. Eur J Heart Fail 2008;10(9):861-868.

35. Melchiorre K, Sutherland GR, Watt-Coote I, et al. Severe myocardial impairment and chamber dysfunction in preterm preeclampsia. Hypertens Pregnancy 2012;31(4):454-471.

36. Hilfiker-Kleiner D, Kaminski K, Podewski E, et al. A cathepsin D-cleaved $16 \mathrm{kDa}$ form of prolactin mediates postpartum cardiomyopathy. Cell 2007;128(3):589-600.

37. Carlin AJ, Alfirevic Z, Gyte ML. Interventions for treating peripartum cardiomyopathy to improve outcomes for women and babies. Cochrane Database Syst Rev 2010;(9): CD008589.
38. Jessup M, Abraham W, Casey D, et al. 2009 Focused update: ACCF/AHA guidelines for the diagnosis and management of heart failure in adults: a report of the American college of cardiology foundation/American heart association task force on practice guidelines developed in collaboration with the international society for heart and lung transplantation. J Am CollCardiol 2009;53(15):1343-1382.

39. McNamara DM, Holubkov R, Starling RC, et al. Controlled trial of intravenous immune globulins in recent-onset dilated cardiomyopathy. Circulation 2001;103:2254-2259.

40. Heart Failure Society of America. Executive summary: HFSA 2006 comprehensive heart failure practice guideline. J Card Fail 2006;12(1):10-38.

41. Abboud J, Murad Y, Chen-Scarabelli C, et al. Peripartum cardiomyopathy: a comprehensive review. Int J Cardiol 2007;118(3):295-303.

42. Williams J, Mozurkewich E, Chilimigras J, et al. Critical care in obstetrics: pregnancy-specific conditions. Best Pract Res Clin Obstet Gynaecol 2008;22(5):825-846.

43. Moioli M, Menada MV, Bentivoglio G, et al. Peripartumcardiomyopathy. Arch Gynaecol Obstet 2010;281(2):183-188.

44. Sliwa K, Skudicky D, Candy G, et al. The addition ofpentoxifylline to conventional therapy improves outcome in patients with peripartum cardiomyopathy. Eur J Heart Fail 2002;4(3):305-309.

45. Dennis AT, Castro JM. Echocardiographic differences between preeclampsia and peripartum cardiomyopathy. Int J Obstet Anaesth 2014;23(3):260-266.

46. Sliwa K, Blauwet L, Tibazarwa K, et al. Evaluation of bromocriptine in the treatment of acute severe peripartum cardiomyopathy: a proof-of-concept pilot study. Circulation 2010;121:1465-1473. 